\title{
Caracterização química e funcional de polpa de Cubiu (Solanun sensiflorum Dunal) liofilizada para consumo em cápsulas
}

\author{
Characterization chemical and functional of pulp Cubiu (Solanun sensiflorum Dunal) lyophilized
}

for consumption in capsules

Caracterización química y funcional dy pulpa de Cubiu (Solanun sensiflorum Dunal) liofirate para

consumo de cápsulas

Recebido: 18/10/2021 | Revisado: 27/10/2021 | Aceito: 03/11/2021 | Publicado: 06/11/2021

\author{
Josiely da Silva de Oliveira \\ ORCID: https://orcid.org/0000-0003-3758-4444 \\ Faculdade Uninorte, Brasil \\ E-mail: josiely.oliveira@ hotmail.com \\ Rosane Silva da Silva \\ ORCID: https://orcid.org/0000-0001-9645-7950 \\ Faculdade Uninorte, Brasil \\ E-mail: rosanesilvalive@ hotmail.com \\ Marcos Túlio da Silva \\ ORCID: https://orcid.org/0000-0002-7653-4944 \\ Faculdade Uninorte, Brasil \\ E-mail: marcostulio39@gmail.com
}

\begin{abstract}
Resumo
O cubiu (Solanum sessiliflorum Dunal) é um dos recursos genéticos nativos da Amazônia, bastante nutritivo, utilizado com diferentes propósitos - medicamento, alimento e cosmético. Assim, o objetivo desse trabalho foi liofilizar e encapsular a polpa de cubiu com a finalidade de averiguar a qualidade do produto através da realização de análises físico-químicas. Trata-se de um estudo experimental, sendo observadas as etapas do tratamento da polpa desde a liofilização até a encapsulação das amostras, a fim de se obter informações a respeito da influência da liofilização na forma de consumo e nas características físico-químicas e funcionais. Foram determinados análise centesimal da polpa com teores de umidade $(90,25 \%)$, proteínas $(0,87 \%)$, lipídeos $(1,92 \%)$, cinzas $(0,78 \%)$, carboidratos $(4,03 \%)$, o valor energético $(33,88 \mathrm{Kcal} / 100 \mathrm{~g})$ e $\mathrm{pH}(3,15)$. Na determinação da concentração do cubiu liofilizado, obteve teores de umidade $(0,0 \%)$, proteínas $(1,96 \%)$, lipídeos $(2,84 \%)$, cinzas $(1,45 \%)$, fibras totais $(4,86)$, carboidratos $(11,11 \%)$, o valor energético $(77,84 \mathrm{Kcal} / 100 \mathrm{~g})$ a concentração de substâncias bioativas como pectina $(2,64 \%)$, ácido ascórbico $(11,86)$, compostos fenólicos $(15,56)$, açúcares redutores $(3,86)$, carotenoides totais $(0,246)$. A maioria dos valores encontrados na determinação da composição da polpa apresenta-se dentro da faixa observada nas literaturas consultadas, normalmente referentes aos frutos produzidos na região Amazônica. O processo de liofilização demonstrou ser eficiente comparado com outros meios de desidratação e o método de encapsulação mostrou ser uma tecnologia com alto potencial podendo ser uma alternativa de grande importância, tanto na questão nutricional e funcional, como na questão logística.
\end{abstract}

Palavras-chave: Cubiu; Liofilização; Composição química; Cápsula.

\begin{abstract}
The cubiu (Solanum sessiliflorum Dunal) is one of the native genetic resources of the Amazon, very nutritious, used for different purposes - medicine, food and cosmetic. Thus, the objective of this work was to freeze and encapsulate the cubiu pulp in order to verify the quality of the product through physicochemical analysis. This is an experimental study, and the stages of pulp treatment are observed from lyophilization to the encapsulation of samples, in order to obtain information about the influence of lyophilization on the form of consumption and physical-chemical and functional characteristics. Centesimal analysis of the pulp with moisture contents $(90,25 \%)$, proteins $(0,87 \%)$, lipids $(1,92 \%)$, ash $(0,78 \%)$, carbohydrates $(4,03 \%)$, energy value $(33,88 \mathrm{Kcal} / 100 \mathrm{~g})$ and $\mathrm{pH}(3,15)$ were determined. In the determination of the concentration of lyophilized cubiu, moisture contents $(0,0 \%)$, proteins $(1,96 \%)$, lipids $(2,84 \%)$, ash $(1,45 \%)$, total fibers $(4,86 \%)$, carbohydrates $(11,11 \%)$, the energy value $(77,84 \mathrm{Kcal} / 100 \mathrm{~g})$ the concentration of bioactive substances such as pectin $(2,64 \%)$, ascorbic acid $(11,86)$, phenolic compounds $(15,56)$, reducing sugars $(3,86)$, total carotenoids $(0,246)$. Most of the values found in the determination of pulp composition are within the range observed in the literature consulted, usually referring to fruits produced in the Amazon region. The lyophilization process proved to be efficient compared with other means of dehydration and the encapsulation method
\end{abstract}


proved to be a technology with high potential and can be an alternative of great importance, both in the nutritional and functional issue, as in the logistics issue.

Keywords: Cubiu; Lyophilization; Chemical composition; Capsule.

\section{Resumen}

El Cubiu (Solanum sessiliflorum Dunal) es uno de los recursos genéticos nativos de la Amazonía, muy nutritivo, utilizado para diferentes propósitos: medicina, alimentos y cosméticos. Así, el objetivo de este trabajo fue congelar y encapsular la pulpa de cubiu con el fin de verificar la calidad del producto a través del análisis fisicoquímico. Se trata de un estudio experimental, y se observan las etapas del tratamiento pulpar desde la liofilización hasta la encapsulación de muestras, con el fin de obtener información sobre la influencia de la liofilización en la forma de consumo y las características físico-químicas y funcionales. Se determinó el análisis centesimal de la pulpa con contenidos de humedad $(90,25 \%)$, proteínas $(0,87 \%)$, lípidos $(1,92 \%)$, cenizas $(0,78 \%)$, carbohydrates $(4,03 \%)$, valor energético $(33,88 \mathrm{Kcal} / 100 \mathrm{~g})$ y $\mathrm{pH}(3,15)$. Al determinar la concentración de cubiu liofilizado, contenido de humedad $(0,0 \%)$, proteínas $(1,96 \%)$, lípidos $(2,84 \%)$, cenizas $(1,45 \%)$, fibras totales $(4,86 \%)$, carbohidratos $(11,11 \%)$, el valor energético $(77,84 \mathrm{Kcal} / 100 \mathrm{~g})$ la concentración de sustancias bioactivas como pectina $(2,64 \%)$, ácido ascórbico $(11,86)$, compuestos fenólicos $(15,56)$, azúcares reductores $(3.86)$, carotenoides totales $(0,246)$. La mayoría de los valores encontrados en la determinación de la composición de la pulpa están dentro del rango observado en la literatura consultada, generalmente referidas a frutas producidas en la región amazónica. El proceso de liofilización demostró ser eficiente en comparación con otros medios de deshidratación y el método de encapsulación demostró ser una tecnología con alto potencial y puede ser una alternativa de gran importancia, tanto en el tema nutricional y funcional, como en el tema logístico.

Palabras clave: Cubiu; Liofilización; Composición química; Cápsula.

\section{Introdução}

A Amazônia é composta em sua rica biodiversidade, por muitas espécies frutíferas pouco exploradas pelos povos que habitam a zona rural e cidades que compõem a região (Yuyama et al. 2007). A grande maioria dessas espécies frutíferas já estão catalogadas pelos órgãos de pesquisas incluindo as universidades e institutos, algumas já são comercializadas nas feiras e mercados locais e fazem parte da gastronomia regional.

Dentre as espécies frutíferas nativas da região Amazônica com propriedades funcionais e nutracêuticos, destaca-se o Cubiu (Solanum Sessiliflorum Dunal) é um dos recursos genéticos nativos da Amazônia que foi completamente domesticado pelos povos indígenas da região (Cruz, 2020). Atualmente é conhecida popularmente no Brasil e em outros países como cubiu, maná, topiro, cocona, tomate de índio, orinoco apple e peach tomato (Silva Filho et al., 2012).

Por ser, um fruto com grande potencial em sua propriedade funcional, tem alto teor de ferro, niacina, ácido cítrico, pectina, compostos fenólicos, carotenoides e ácidos ascórbico sendo utilizados em tratamentos medicinais. Usados em diversos problemas de saúde, onde utilizam as folhas, raízes e frutos empregados na produção de medicamentos naturais, cosméticos e como alimentos consumidos in natura em saladas juntamente com verduras e legumes (Augusto, 2020). O fruto é exótico, possui sabor ácido, tendo potencial e múltipla forma de uso como sucos, doces, geleias, compotas, molhos para temperar carnes em geral, cosméticos e medicamentos caseiros. Sendo considerado um excelente produto com sabor ácido, com diferentes propriedades como um alto teor de pectina e com boas características nutricionais (Silva Filho, et al. 2005). Uma de suas principais funções é a utilização no tratamento de diversas doenças da anemia, da pelagra e, principalmente, no controle dos níveis elevados de colesterol, ácido úrico e glicose no sangue (Pires, et al., 2020).

Os consumidores estão mais exigentes por produtos saudáveis, de qualidade e com praticidade, no que se refere a produtos que possam oferecer uma "garantia de saúde", seja ele enriquecido por alguma substância ou com baixo teor de outras (Konig, 2016). Contudo, é necessário que o produto seja bem conservado, pois faz com que aumente seu tempo de vida útil, impedindo que a atividade microbiana altere as propriedades sensoriais e nutricionais do produto. Um dos responsáveis pelas alterações indesejáveis é o fator de umidade presente nos alimentos. Remover a água ou a maior parte dela é de suma importância para comercialização e transporte de muitos produtos perecíveis (Medeiros, 2006). 
Uma técnica que vem ganhando espaço na indústria alimentícia é a liofilização que visa preservar o produto, desidratando e mantendo as propriedades nutritivas do alimento, mantendo as características naturais. O processo de liofilização se mostra eficiente comparado com outros meios de desidratação, frente às características como contração do produto, perda de voláteis, decomposição térmica, ações enzimáticas e desnaturação de proteínas, por isso merece destaque (Garcia, 2009).

Portanto, por se tratar de uma frutífera com inúmeras características benéficas ao homem, se faz necessário a análise química e funcional desse cultivo, para que se produza cápsula contendo cubiu liofilizado, a fim de modificar a forma de apresentação e consumo. As principais finalidades da encapsulação de matérias-primas são: reduzir as interações do conteúdo com fatores externos, retardando alterações que podem resultar em perda das características organolépticas e do valor nutricional evitando reações prematuras de um substrato; mascarar compostos de sabor indesejável; promover melhor solubilidade do núcleo e melhor incorporação em sistemas secos (Azeredo, 2005). A demanda de alimentos liofilizados e encapsulados vem crescendo muito nos últimos anos principalmente para aqueles alimentos cujo sabor não seja tão agradável, mas que apresentam grandes propriedades nutricionais. Sendo assim, o objetivo deste trabalho foi liofilizar e encapsular a polpa de cubiu com a finalidade de averiguar a qualidade do produto final através da realização de análises físico-químicas. Além, de aumentar a vida útil do produto, reduzindo a violabilidade e degradação oxidativa, tendo assim um produto de qualidade com maior valor agregado (Clark, 2002).

\section{Metodologia}

Os frutos utilizados neste estudo, foram coletados na estação experimental do Instituto Nacional de Pesquisas da Amazônia - INPA localizada na reserva do Ariaú estrada de Manacapuru, km 18, em estádio de maturação, onde foi devidamente condicionado e transportado para o laboratório do Instituto, onde passaram por um processo de seleção, com a eliminação de frutos impróprios para a produção de polpa liofilizada. Para seleção dos frutos foi feito um processo de seleção, descartando-se os imaturos e amassados, sendo utilizados os frutos que se encontravam morfologicamente perfeitos. Os testes foram realizados no laboratório de bioquímica e fisiologia pós-colheita do INPA para a determinação da composição centesimal do fruto onde foram analisados: umidade, proteínas, lipídios, fibra totais, carboidrato, valor energético, $\mathrm{pH}$ e cinzas. Além da composição centesimal, foram feitas do cubiu liofilizado as seguintes análises: teor de pectina, fenólicos, ácido ascórbico, açucares redutores, carotenoides totais.

A lavagem dos frutos do cubiu foi realizada com água potável, proveniente da torneira, o sistema de lavagem foi realizado por imersão seguido de agitação utilizando-se água corrente. A sanitização foi feita por imersão em solução de hipoclorito de sódio na concentração de 200 PPM durante 15 minutos, seguida de enxague em água corrente e drenagem usando-se peneiras. Após a desinfecção dos frutos de cubiu, os mesmos foram cortados em rodelas com facas de aço inox, em seguida foi feito o branqueamento.

O branqueamento foi realizado pelo sistema de banho-maria em tacho aberto de aço inoxidável, contendo água em ebulição $\left(80^{\circ} \mathrm{C}\right)$ aquecida em fogão a gás, onde foi imerso na água 3,5 $\mathrm{kg}$ do fruto cortado em fatias com casca e sementes de cubiu por 15 minutos para inativação enzimática e eliminação de microrganismo. Para o resfriamento, os frutos cortados foram submergidos até o total resfriamento com gelo, em seguida, o material foi retirado até atingir a temperatura próxima ao ambiente. Após o resfriamento, o produto foi processado no aparelho liquidificador devidamente sanitizado, com todas as medidas de higiene na manipulação, para evitar contaminação de microrganismos. A polpa foi peneirada somente para retiradas de partes que não foram trituradas. Em seguida, foi transferida para embalagens de sacos de polietileno fechados, com capacidade para $1 \mathrm{~kg}$ e armazenados em freezer com temperatura de $-19^{\circ} \mathrm{C}$. 
Após o tempo de congelamento da polpa, o material foi colocado no liofilizador marca Terroni - modelo LS3000 por 48 horas; as amostras liofilizadas foram trituradas no liquidificador até a completa pulverização do produto, deixando ao ponto de encapsular; em seguida colocadas numa encapsuladora manual em acrílico Aeronáutico - tipo 00 para encapsulamento do produto através do agente encapsulante semi-sintético; após esta etapa, armazenadas em frascos com 60 cápsulas, e finalizado com a rotulagem.

Para realizar a comparação das substâncias bioativas, foi feito também o processo do cubiu seco em estufa, onde no tratamento a polpa foi colocada em bandejas de aço inox; em seguida levado para estufa com circulação forçada de ar a $65^{\circ} \mathrm{C}$ por 72 horas, depois retirado o material seco e triturado em liquidificador até a sua pulverização.

As principais etapas do experimento estão mostradas no fluxograma (Figura 1) e descritas a seguir:

Figura 1: Fluxograma de obtenção da polpa de cubiu liofilizada e secagem em estufa.

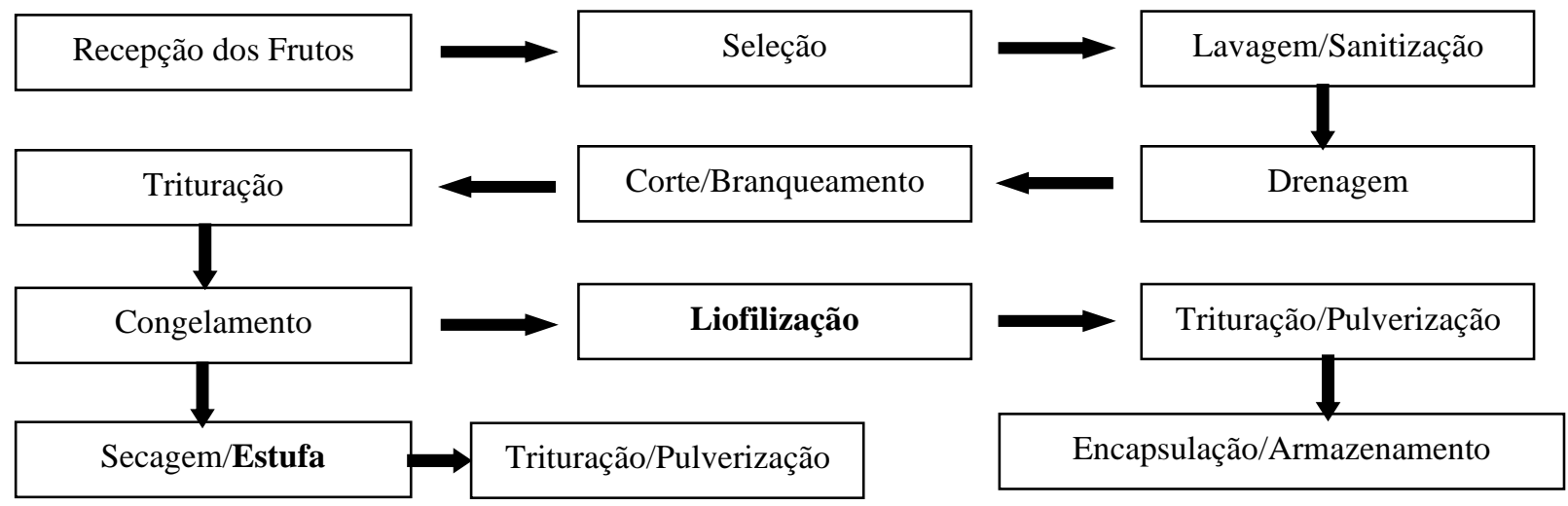

Fonte: Autores.

\subsection{Delineamento experimental e análise estatística dos dados}

O estudo realizado é do tipo experimental sendo observadas as etapas do tratamento da polpa desde a liofilização até a encapsulação das amostras, a fim de se obter informações a respeito da influência da liofilização na forma de consumo e nas características físico-químicas e funcionais do cubiu. O delineamento experimental foi inteiramente casualizado em cada um dos experimentos. Os dados foram submetidos à análise de variância (ANOVA) e as médias foram comparadas pelo teste de Tukey a 5\% de probabilidade, pelo programa ASSISTAT (Granada et al., 2005).

\subsection{Caracterização da análises físico-químicas dos frutos de cubiu}

A caracterização das análises físico-químicas dos frutos de cubiu se desenvolveu analisando cada componente centesimal do produto e os compostos bioativos.

$\mathrm{O}$ teor de umidade foi determinado por dessecação do material em estufa a $65^{\circ} \mathrm{C}$ com circulação forçada de ar até peso constante (Ranganna, 1986). Os teores de sólidos solúveis totais foram determinados por leitura em um refratômetro digital (HI 96801 REFRACTOMETER, precisão $0,2 \%$ ) com escala de $0^{\circ} \mathrm{C}$ Brix a $85^{\circ} \mathrm{C}$ Brix, devidamente calibrado com água destilada. Algumas gotas da amostra foram colocadas sobre o prisma do aparelho e procedeu-se a leitura direta dos ${ }^{\circ} \mathrm{C}$ Brix indicado pelo aparelho.

Para as análises do $\mathrm{pH}$ a leitura foi feita em pHmetro marca digital, Modelo UP- 25, pH /mV/ Ion Meter, (DENVER INSTRUMENT) seguindo de acordo com as normas estabelecidas pelo Instituto Adolfo Lutz (2008). 
As fibras totais foram determinadas em refrigerante de refluxo usando-se a amostra seca e desengordurada, submetida à lavagem ácida e básica, lavada com água quente e filtrada. Posteriormente o resíduo foram mantidos em estufa a $105^{\circ} \mathrm{C}$ por uma hora e depois pesado. Os resultados foram expressos em g/100g de matéria integral (Instituto Adolfo Lutz, 2008).

As cinzas foram determinadas por incineração do material seco e desengorduradas em mufla a $550^{\circ} \mathrm{C}$ por aproximadamente cinco horas (AOAC, 1990). O teor de proteína foi obtido por cálculos onde foi utilizado o fator 6,25 para conversão do nitrogênio total em proteína (AOAC, 1990).

Valor calórico total, foi calculado segundo a Resolução - RDC n 360 de 23 de dezembro de 2003 (ANVISA, 2003).

Os lipídios foram determinados através de extrator Soxhlet marca Marconi e modelo MA1876, utilizando-se a amostra seca e o éter de petróleo como solvente. Os resultados foram expressos em percentagem (Instituto Adolfo Lutz, 2008). Os carboidratos foram determinados por diferença, subtraindo-se de 100 os valores obtidos para proteínas, lipídios, fibras, cinzas e umidade. O ácido ascórbico foi extraído com solução de ácido oxálico a 0,5\% e quantificado por titulação com solução de 2,6 diclorofenol indofenol, segundo Ranganna (1986). Foi utilizado para os cálculos o padrão com solução (100 $\mu \mathrm{g} / \mathrm{ml}$ ) de ácido ascórbico P.A. cujos resultados serão expressos em mg/100 de polpa.

Os compostos fenólicos foram extraídos seguindo a metodologia de Goldstein e Swain (1963). Os compostos fenólicos foram quantificados pelo método de Folin Ciocalteau descrito por Cliffe et al. (1994). A curva padrão foi feita com ácido tânico, os resultados foram calculados pela equação da reta e expressos em $\mathrm{mg} / 100 \mathrm{~g}$ de matéria. As amostras foram lidas em espectrofotômetro em absorbâncias de 374nm para flavonoides. Os coeficientes de extinção de 98,2 e 76,5, foram utilizados, para flavonoides, cujos resultados foram expressos em $\mathrm{mg} / 100 \mathrm{~g}$ de matéria. Após a pesagem das amostras, os carotenoides totais foram extraídos com os solventes orgânicos hexano e álcool iso-propílico. A leitura da absorbância foi feita em espectrofotômetro a 450nm. Os resultados foram expressos em $\mathrm{mg}$ de carotenoides totais em $\mathrm{g} / 100 \mathrm{~g}$ de matéria (Higby, 1962).

Após a pesagem das amostras, os carotenóides totais foram extraídos com os solventes orgânicos hexano e álcool isopropílico. A leitura da absorbância foi feita em espectrofotômetro a 450nm. Os resultados foram expressos em mg de carotenóides totais em g/100g de matéria integral (Higby, 1962).

As pectinas foram quantificadas segundo a metodologia descrita por Ahmed; Labavitch (1977). A curva padrão foi feita com ácido galacturônico nas concentrações de 20 a $100 \mu \mathrm{g} / \mathrm{mL}$, os resultados foram calculados pela equação da reta e expressos em $\mathrm{mg} / 100 \mathrm{~g}$ de matéria integral.

\section{Resultados e Discussão}

\subsection{Resultados}

\subsubsection{Caracterização da polpa}

A composição química da polpa de cubiu está apresentada na Tabela 1. Os valores obtidos correspondem à composição nutricional do cubiu realizadas através da análise centesimal. 
Tabela 1. Composição química e nutricional do Cubiu (Solanum Sessiliflorum Dunal) em 100g de polpa.

\begin{tabular}{cc}
\hline Componentes $\mathbf{~} / \mathbf{1 0 0 g}$ & Polpa com semente e casca \\
\hline Umidade & 90,25 \\
Proteínas totais & $0,87 \pm 0,6$ \\
Lipídeos & $1,92 \pm 0,8$ \\
Cinzas & $0,78 \pm 0,5$ \\
Fibras totais & $2,10 \pm 0,7$ \\
Carboidratos & 4,03 \\
Valor energetico $(\mathrm{kcal})$ & 36,88 \\
pH & 3,15 \\
Sólidos solúveis $\left({ }^{\circ} \mathrm{Brix}\right)$ & 5,80 \\
\hline
\end{tabular}

Fonte: Análise de dados realizados pelos autores.

A Tabela 1, apresenta dados obtidos da polpa do cubiu in natura.

Tabela 2. Composição química de polpa de Cubiu liofilizado (Solanum Sensiflorum Dunal) em 100g de amostra.

\begin{tabular}{cc}
\hline Componentes $\mathbf{~} / \mathbf{1 0 0 g}$ & Cubiu liofilizado \\
\hline Umidade & 0,0 \\
Proteínas totais & $1,96 \pm 04$ \\
Lipídeos & $2,84 \pm 0,5$ \\
Cinzas & $1,45 \pm 0,6$ \\
Fibras totais & $4,86 \pm 0,3$ \\
Carboidratos & 11,11 \\
Valor energetic (kcal) & 77,84 \\
\hline
\end{tabular}

Fonte: Análise de dados realizados pelos autores.

A Tabela 2 mostra que após a liofilização do fruto o cubiu perdeu toda umidade, pois esse processo de liofilização é usado principalmente para remover água do produto, ou seja, ausência de água no alimento faz com que esses produtos se conservem por um grande período em temperatura ambiente, pois resulta também na extinção de micro-organismos que necessitam de água para sobreviver e que degradam o alimento. $\mathrm{O}$ teor de cinzas foi encontrado em maior quantidade no cubiu liofilizado do que na polpa. A polpa liofilizada também obteve maior teor de lipídios e carboidrato. O valor energético revelou um teor mais alto para o fruto liofilizado com concentração 77,84 kcal.

Tabela 3. Substâncias bioativas em amostra de Cubiu seco em estufa e liofilizado (mg/100g).

\begin{tabular}{cccccc}
\hline Amostras & Pectina & Fenólicos & $\begin{array}{c}\text { Ácido } \\
\text { ascórbico }\end{array}$ & $\begin{array}{c}\text { Açúcares } \\
\text { redutores }\end{array}$ & $\begin{array}{c}\text { Carotenoides } \\
\text { totais }\end{array}$ \\
\hline $\begin{array}{c}\text { Cubiu seco } \\
\text { em estufa }\end{array}$ & $1,83 \pm 0,2$ & $12,35 \pm 0,2$ & $9,57 \pm 0,2$ & $2,72 \pm 0,1$ & $0,192 \pm 0,6$ \\
$\begin{array}{c}\text { Cubiu } \\
\text { liofilizado }\end{array}$ & $2,67 \pm 0,5$ & $15,56 \pm 0,4$ & $11,86 \pm 0,3$ & $3,86 \pm 0,4$ & $0,246 \pm 0,3$ \\
\hline
\end{tabular}

Fonte: Análise de dados realizados pelos autores. 
A tabela 3 mostra que na análise do cubiu liofilizado apresentou maiores concentrações de substâncias, com alto teor de pectina, ácido ascórbico, açúcares redutores, carotenoides e composto fenólicos em comparação ao cubiu seco em estufa que ficou em torno de 1,83mg. O teor de ácido ascórbico foi superior no cubiu liofilizado com concentração de 3,86mg. O maior teor para pectina foi encontrado no cubiu liofilizado, em torno de 2,67mg. Os resultados bioativos, equivalente aos dados recomendando para ser considerado um produto nutracêutico com caraterística funcional.

\subsection{Discussão}

Com base nos resultados obtidos na análise especificado acima e comparando aos encontrados nas pesquisas literárias, eles estão dentro da faixa observada, em acordo com valores obtidos pelos teóricos Pereira (2001); Yuyama et al. (2002); Augusto (2020). O cubiu apresentou alto teor de umidade na polpa em torno de 90,25\% (Tabela 1), esse valor está equiparado a resultados encontrados no estudo elaborado por Yuyama et al. (2007), esse dado reflete a consistência suculenta da fruta; e o sabor ácido acentuado é confirmado pelo valor do $\mathrm{pH}(3,15)$, resultados estes similares nos trabalhos elaborados por Silva Filho (2009); Freitas (2011). Geralmente, o pH da polpa no processo de branqueamento do cubiu, aumenta em relação à polpa in natura e consequentemente a acidez aumenta melhorando a sua aceitabilidade após pasteurização.

A concentração de lipídeos determinada neste trabalho foi de 1,92g/100g como mostra a Tabela 1 , sendo inferior ao valor encontrado no trabalho de Pires, et al. (2020) de 2,23g. As condições edafoclimáticas, a forma de cultivo e adubação, são fatores que interferem diretamente na planta podendo aumentar ou diminuir a concentração dos nutrientes e substâncias bioativas presentes no fruto.

O teor de carboidratos, cujo valor encontrado é de 4,03g/100g é inferior aos disponíveis na literatura, conforme o resultado obtido por Agudelo et al. (2016), onde a concentração de carboidrato foi de 6,00\%. O valor de carboidrato demostra claramente que o cubiu não é um fruto calórico e que pode ser consumido em grande quantidade. O teor de proteínas de 0,87 g/100g e cinza 0,78 g/100g colaboram com valores aproximados aos dados estabelecidos no estudo elaborado por Pires, et al. (2020), que obteve valores de proteínas $0,82 \%$, e cinza $0,77 \%$. Os níveis de proteínas totais no cubiu demonstram que o fruto está de acordo com a maioria dos vegetais, mas que tem seu valor somado a outros alimentos.

A concentração de fibras totais apresentou uma quantidade de $2,1 \pm 0,7 \mathrm{~g} / 100 \mathrm{~g}$. Nesse contexto, o fruto torna-se adequado para consumo humano, pois trazem suas vantagens funcionais, principalmente o fruto in natura, ou mesmo em formulações alimentícias ou até na forma de produto encapsulado. As fibras desempenham funções benéficas à saúde, favorecendo a funcionalidade intestinal, quando associadas a um bom consumo de água, pois podem atuar diminuindo o tempo do trânsito intestinal, retardando o esvaziamento gástrico, aumentando o volume fecal e tem capacidade de diluir compostos potencialmente tóxicos e cancerígenos, além de dar saciedade (Catalani, et al., 2003).

Com os resultados adquiridos, podemos observar que houve baixa concentração de carboidratos e baixo valor energético do cubiu (Tabela 1), pois são características típicas do fruto, e esses dados não diferem dos resultados da literatura esplanada, conforme cita Pahlen (1977). Dessa maneira, esse fruto pode ser considerado uns dos frutos da Amazônia com grande potencial pelo fato do mesmo ter baixa densidade energética, constituindo, uma forma de ser inserido na alimentação de pacientes com restrição alimentar como o caso dos sobrepesos, obesos e diabéticos.

$\mathrm{O}$ pH e o teor de sólidos solúveis $\left({ }^{\circ} \mathrm{C}\right.$ Brix) dos frutos estiveram entre 3,15 e 5,8 indicando pequena diferença entre as variáveis estudadas. Valores semelhantes foram apresentados nas literaturas observadas, onde vários autores concluíram que, os frutos de cubiu possuem características físico-químicas apropriadas para a elaboração especialmente de geleias e diversas outras derivações, devido ao seu potencial de aproveitamento. Esses frutos também são de fácil manuseio, pouco perecíveis, de consistência firme e boa rentabilidade. 
Em comparação da polpa in natura (tabela 1) com a polpa liofilizada (tabela 2), o cubiu liofilizado apresentou maior teor de resíduo mineral fixo (cinzas), lipídeos, proteína, fibras solúveis, incluindo um maior teor de carboidrato e valor energético. Já a polpa do cubiu in natura apresentou teores baixos de lipídeos e carboidratos em todas as partes analisadas conforme Tabela 1, revelando-se uma fruta de baixo valor calórico sendo uma opção para complementar a alimentação de indivíduos com sobrepeso, obesidade ou aqueles com restrição energética, como sugere Yuyama et al, (2007). O cubiu liofilizado se destacou pelo alto teor de fibras, principalmente insolúveis (Tabela 2) em relação ao resultado nas análises da polpa, possivelmente devido a concentração de substancia através do processo de desidratação utilizada.

Quanto ao teor de cinzas, é possível observar uma diferença significativa entre a polpa in natura e a liofilizada, o processo provocou um aumento no teor de cinzas, o resultado mais expressivo foi observado na liofilização. Exemplificando, e comparando o quanto a liofilização aumentam os resultados, Bezerra (2014) em seus estudos sobre a polpa de marolo liofilizada, também observou um aumento em seus resultados que passou de 1,42\% in natura para 3,32\% liofilizada no teor de cinzas. Os resultados expressos para os teores de lipídeos mostram que houve diferença significativa entre os tratamentos apresentados para as polpas de cubiu, no entanto, houve um aumento no teor de lipídeos na polpa liofilizada (2,84\%) quando comparada com a polpa in natura $(1,92 \%)$.

Ao liofilizar um produto, ocorre toda eliminação de água existente com eficiência, devido ao uso do vácuo e baixas temperaturas. E na obtenção dos resultados pós liofilização, os valores químicos e nutricionais apresentaram quantidades elevadas em comparação aos dados da polpa.

Os resultados apresentados na Tabela 3 mostram que houve diferenças significativas entre os grupos de tratamentos, cubiu seco em estufa e cubiu liofilizado, indicando que a polpa liofilizada se sobressaiu em relação ao cubiu seco em estufa. Com relação aos resultados do teor de ácido ascórbico, houve diferença significativa para a polpa liofilizada. É possível observar que após processo de liofilização houve um aumento no teor de Ácido Ascórbico das amostras liofilizadas como mostra a tabela 3 (11,86mg) respectivamente. Esses resultados, podem ser comparados aos estudos de Vieira et al., (2015), que analisar polpa de acerola in natura, encontrou teor de vitamina C de 416,14 (mg/100g) e após a liofilização o teor de vitamina C foi elevado para 1.571,05 (mg/100g). Esse aumento estar relacionado à alta concentração promovida pelo processo de liofilização após a retirada da água. Os resultados obtidos na tabela 3 mostram os dados com valores de substancia essenciais para manutenção do corpo humano. Segundo a Agência Nacional de Vigilância Sanitária (2010), são aprovadas alegações de propriedades funcionais ou de saúde para o produto final que tenha ingredientes ou componentes funcionais. Mediante a base desses dados, o cubiu pode ser considerado um alimento funcional, pois apresenta em sua composição química, substancias bioativas como fenólicos, carotenóides, pectinas e ácido ascórbico que segundo Kruger e Mann (2003) trazem benefícios terapêuticos a saúde se consumidos corretamente.

Além dos macros e micronutrientes essenciais, existentes, o fruto fornece alguns compostos bioativos, que contribuem na função da atividade biológica. Arabbi (2004), enfatiza que, esses compostos podem desempenhar diversos papéis em benefício da saúde.

O processo de liofilização merece destaque por apresentar eficiência comparada com outros meios de desidratação, como contração do produto, perda de voláteis, decomposição térmica, ações enzimáticas e desnaturação de proteínas (Garcia, 2009). Vale ressaltar, seguindo essa linha de pensamento, os produtos naturais desidratados por liofilização estão atualmente ocupando o mais alto patamar de qualidade e praticidade nos meios industriais, substituindo com vantagens na praticidade os produtos "in natura" e em qualidade, os produtos sintéticos (Eblsa, 2020).

Os frutos liofilizados apresentam alta retenção das características sensoriais e qualidade nutricional, com vida de prateleira maior quando corretamente embalados e permanecendo em temperatura ambiente. Os compostos aromáticos voláteis 
não são absorvidos pelo vapor d'água. Obtém também maior facilidade em seu transporte, devido à sua leveza e por não necessitarem de refrigeração, acarretando um menor custo no transporte (Evangelista, 2005).

Além de se obter um produto de qualidade, alto potencial, reduzindo o desperdício e as perdas pós-colheita. A liofilização é o melhor método de secagem para materiais termo sensíveis e para a obtenção de produtos desidratados com elevada qualidade. Consequentemente, as frutas liofilizadas são usadas na preparação de sucos naturais substituindo as polpas congeladas; como sabores e aromas naturais para bebidas, fitoterápicos em cápsulas ou em barras vegetais, em iogurtes, bolos e sorvetes, mix práticos para viagens e passeios ecológicos e também como produtos cosméticos (Terroni et al., 2013).

Após todo processo da liofilização, se fez uso da encapsulação do produto liofilizado, pois apresenta como um processo de grande importância para a indústria de alimentos gerando impactos positivo. No entanto, esse processo envolve a incorporação de ingredientes naturais, polifenóis, aditivos voláteis, enzimas e bactérias (bactérias lácticas atuando como probióticos). Em pequenas cápsulas, proporcionando a estabilidade dessas moléculas, protegendo e preservando contra possíveis perdas nutricionais e, eventualmente, para atuar como agentes antimicrobianos (Souza, et al., 2021).

\section{Conclusão}

O cubiu (Solanum Sessiliflorum Dunal) revela-se um produto regional com elevado potencial com características funcionais, devido às suas propriedades agronômicas, nutricionais, medicinais e tecnológicas. O processo de liofilização demonstrou-se eficiente comparado com outros meios de desidratação, o fruto fornece alguns compostos químicos, presentes, que exercem uma potente atividade biológica, já comprovada por alguns pesquisadores, pois desempenham diversos benefício à saúde, os chamados compostos bioativos, presentes na polpa do fruto.

Diante disso, este trabalho nos mostra que o processo de liofilização e encapsulação, são uma alternativa de grande importância no campo nutracêutico, pois aumentam a concentração de compostos bioativos e na questão logística, há a facilidade de administrar, transportar e armazenar, devido ao menor volume apresentado por esse produto. Por serem tecnologias com alto potencial para aumentar a sobrevida dos alimentos, são considerados métodos seguros, porém, alguns cuidados devem ser seguidos com as condições do ambiente, como teor de água e com a utilização de embalagens adequadas para melhor estabilidade do produto, pois a utilização de um material encapsulante adequado é de extrema importância para a retenção de compostos voláteis.

Portanto, espera-se que num futuro próximo, esse trabalho sirva de referência para a agroindústria na produção de cubiu liofilizado e que atenda a demanda de consumo, incentivando a produção rural do cubiu por pequenos e médios agricultores da região Amazônica, fixando o homem ao campo, agregando valor ao produto, gerando renda e melhorando a qualidade de vida das comunidades envolvidas.

\section{Agradecimentos}

Primeira a Deus, pela nossa vida, e por nos permitir ultrapassarmos todos os obstáculos encontrados durante todos os anos de nossos estudos, e na realização deste trabalho, na qual nos direcionou pessoas maravilhosas que contribuíram para que esta pesquisa fosse realizada, em meio as dificuldades. Gratidão por nos guiar sempre.

Aos nossos pais, irmãos e esposos, que nos incentivaram nos momentos difíceis e compreenderam nossas ausências, enquanto nos dedicávamos à realização deste trabalho.

Ao nosso Professor Msc Marcos Túlio da Silva, por ter sido nosso orientador e ter desempenhado tal função com dedicação e amizade. Obrigado pela confiança, paciência e dedicação de seu tempo em nos conduzir de forma admirável.

A todos professores, por todos os conselhos, pela ajuda e pela paciência com a qual guiaram nosso aprendizado. 
Ao INPA (Instituno Nacional de Pesquisas da Amazônia) que por meio do Professor Msc Raimundo Souza conseguimos realizar as análises em laboratório.

A todos que participaram, direta ou indiretamente do desenvolvimento deste trabalho de pesquisa, enriquecendo o nosso processo de aprendizado.

Às pessoas com quem convivemos ao longo desses anos de curso, que nos incentivaram e que certamente tiveram impacto na nossa formação acadêmica.

Por fim, à Universidade UNINORTE/SER quero deixar uma palavra de gratidão por ter nos recebidos de braços abertos e com todas as condições que nos proporcionaram dias de aprendizagem.

\section{Referências}

Agudelo, C., Igual, M., Moraga, G., \& Navarrete, N. M. (2016). Implicação da atividade de água nos compostos bioativos e nas propriedades físicas de cocona (Solanum sessiliflorum Dunal) Chips. Food Bioprocess Technol, (9):161-171.

Ahmed, A. R., \& Labavittch, J. M. (1977). A Simplified method for accurate 153 determination of cell wall uronid content. Journal of Food Biochemistry, p. 361-65

Agência Nacional de Vigilância Sanitária.-ANVISA (2010). VIII-Lista de novos alimentos aprovados. http://www.anvisa.gov.br/alimentos/co missoes/novos_alimentos.html.

Agência Nacional de Vigilância Sanitária.-ANVISA (2003). Resolução RDC nº 360, de 23 de dezembro de 2003. Aprova Regulamento Técnico sobre Rotulagem Nutricional de Alimentos Embalados, tornando obrigatória a rotulagem nutricional. https://www.gov.br/agricultura/ptbr/assuntos/inspecao/produtos-vegetal/legislacao-1/biblioteca-de-normas-vinhos-e-bebidas/resolucao-rdc-no-360-de-23-de-dezembro-de-2003.pdf/view.

AOAC, Official Methods of analysis. (1990). Association of Official Analytical Chemusts. Arlington, EUA.

Arabbi, P.R. et al. (2004). Flavonoids in vegetables foods commonly consumed in Brazil and estimated ingestion by the Brazilian population. Journal Agricultural. Food Chemistry, p.1124-31.

Augusto, E. (2020). Maná-cubiu: a fruta dos deuses. http://www.bioflorestal.com.br/mana_novo.html.

Azeredo, H. M. C. (2005). Encapsulação: aplicação à tecnologia de alimentos. Araraquara. 16(1), 89-97

Bezerra, T. S. (2014). Caracterização física, química e morfológica de polpa de marolo liofilizada. Universidade Federal de Lavras. 141.

Catalani, L. A. et al. (2003). Fibras alimentares. Rev Bras Nutr Clin, 18(4), 178-182.

Clark, J. P. (2002). Food encapsulation: capturinganesubstance by another. Products \& Technologies Processing, 56(11), 63-65.

Cliffe, S., Fawer, M. S., Maier, G., Takada, K., \& Ritter, G. (1994). Enzyme assays for the phenolic content of natural juices. Journal Agricultural Food Chemistry, 42, 1824-1828.

Cruz, R. P. (2020). Processamento, características físico-químicas e sensoriais de picles de Cubiu (Solanum sessiliflorum Dunal). https://repositorio.inpa.gov.br/bitstream/1/5348/1/Disserta\%c3\%a7\%c3\%a3o\%20final-\%20Raydson\%20Vers\%c3\%a3o\%20Digital.pdf

Eblsa. (2020). Aplicação de produtos liofilizados na indústria. http://www.eblsa.com.br.

Evangelista, J. (2005). Tecnologia de Alimentos. Atheneu. (2a ed.).

Freitas, F. M. N. O. (2011). Obtenção do cubiu (Solanum sessiliflorum Dunal) em passa por métodos combinados. Tese (Doutorado). Programa Multiinstitucional de Pós-graduação de Dourorado em Biotecnologia. Universidade Federal do Amazonas, Manaus, Amazonas, p.95.

Garcia, L. P. (2009). Liofilização aplicada a alimentos. Universidade Federal de Pelotas, p. 45.

Goldstein, J.L., \& Swain, T. (1963). Changes in the tannins in ripening fruits. Phyto chemistry. 2, 371-383.

Granada, G. G., Zambiazi, R. C., Mendonça, C. R. B., \& Silva, E. (2005). Caracterização física, química, microbiológica e sensorial de geleias light de abacaxi. Ciência e Tecnologia de Alimentos, 25 (4): 629-635.

Higby, W. K. A. (1962). A simplified method for determination of some the carotenoid distribuition in natural and carotene fortified orange juice. Journal of Food Science, v. 27, p. 42-49

Instituto Adolfo Lutz. (2008). Métodos físico-químicos para análise de alimentos. digital. 1020p.

Konig, L. D. (2016). Liofilização Aplicada A Produtos Cárneos Avícolas. https://repositorio.utfpr.edu.br/jspui/bitstream/1/1330 2/1/liofilizacaoaplicadaprodutoscarneos.pdf.

Kruger, C. L., \& Mann, S. W. (2003). Safety evaluation of funcional ingredients. Food and Chemical Toxicology. 41, 793-805. 
Research, Society and Development, v. 10, n. 14, e380101421993, 2021

(CC BY 4.0) | ISSN 2525-3409 | DOI: http://dx.doi.org/10.33448/rsd-v10i14.21993

Medeiros, M. L. et al. (2006). Sorption isotherms of cocoa and cupuaçu products. Journal of Food Engineering, 73(4), 402-406.

Pahlen, A. V. D. (1977). Cubiu [Solanum topiro (Humb \& Bonpl.)], uma fruteira da Amazônia. Acta Amazonica, 7(3): 301-307.

Pereira, Z. R. F. (2001). Efeito hipoglicêmica da fibra do cubiu (Solanum sessiliflorum Dunal) em ratos diabéticos. Universidade do Amazonas, 63p.

Pires, A. M. B. et Al. (2020). Caracterização e Processamento De Cubiu (Solanum sessiliflorum). https://www.redalyc.org/articulo.oa?id=305226699004.

Ranganna, S. (1986). Analyses and quality control for fruit and vegetable products. New Delhi: Products Tata Mc Graw-Hill Pulishing, 1112 pp.

Silva Filho, D. F. et al. (2005). Caracterização e avaliação do potencial agronômico e nutricional de etnovariedades de cubiu (SolanumsessiliflorumDunal) da Amazônia. Acta Amazônica, 35(4), 399-406.

Silva Filho, D. F. et al. (2002). Discriminação de etnovariedades de cubiu (SolanumsessiliflorumDunalSolanaceae) da Amazônia, com base em suas características morfológicas e químicas. INPA/UFAM. Manaus, AM. Tese de Doutorado. 117 p.

Silva Filho, D. F. et al. (2009) Domesticação e melhoramento de hortaliças amazônicas. In: Domesticação e melhoramento: espécies amazônicas. Viçosa, MG. p 461-486.

Silva Filho, D. F., Soares, J. E. C., Vasques, M. S., Martins, A. L. U., Noda, H., Machado, F. M., \& Noda, S. N. (2012). Potencial das etnovariedades de cubiu (Solanum sessiliflorum Dunal, Solanaceae) da região do alto rio negro, avaliado por análises morfológica e agronômica. In: Souza, L. A. G., Castellón, E. G. (Ed.). Desvendando as fronteiras do Conhecimento na Região Amazônica do Alto Rio Negro. Manaus: INPA, p.147-169.

Souza A. L. R, Rodrigues F. M., Silva G. V., \& Santos R. R. (2021). Microencapsulação de sucos e polpas de frutas por spray drying: uma revisão. http://www.deag.ufcg.edu.br/rbpa/rev173/Art17314.pdf.

Terroni H. C., DE Jesus J. M., Artuzo L. T., Ventura L. V., Santos R. F., \& Damy-Benedetti P. de C. (2013) Liofilização, Revista Científica Unilago, V. 1.

Vieira, A. C. A. et al. (2015). Caracterização físico-química de polpa de acerola in natura e liofilizada para preparação de sorvetes. Blucher Chemical Engineering Proceedings, 1(2), 3542-3546.

Yuyama, L. K. O. et al. (2007). Macro and micro nutrients quantification of some cubiu ethnovarieties (Solanum sessiliflorum Dunal). Acta Amaz., Manaus, vol.37 no.3.

Yuyama, L. K. O. et al. (2002). (. Quantificação de fibra alimentar em algumas populações de cubiu (Solanum sessiliflorum Dunal), camu-camu (Myrciaria dubia (H.B.K) McVaugh) e açaí (Euterpe oleracea Mart). Acta Amazônica 32(3): 49-497. 